\title{
Regimes de Endividamento, Fragilidade Financeira e Dinâmica da Atividade Produtiva
}

\author{
Antonio J. A. Meirelles \\ Gilberto Tadeu Lima
}

\author{
Professor, UNICAMP - Faculdade de Engenharia de Alimentos \\ Professor, FEA/USP - Departamento de Economia
}

\section{RESUMO}

Elabora-se um modelo pós-keynesiano de utilização e crescimento da capacidade produtiva, no qual a oferta de moeda de crédito é endógena e o endividamento das firmas é explicitamente modelado. A taxa de juros é determinada pela aplicação de um mark-up sobre a taxa básica fixada pela autoridade monetária. O mark-up bancário varia intertemporalmente em conseqüência de mudanças no nível de atividade econômica, medido pela utilização da capacidade produtiva. Por seu turno, o grau de endividamento das firmas varia em função das taxas de lucro, de acumulação de capital físico e de juros. Em termos dinâmicos, mostra-se que é possível relacionar as condições de estabilidade do sistema formado pelas variáveis taxa de juros e grau de endividamento das firmas ao tipo de regime minskyano de financiamento - hedge, especulativo ou Ponzi - prevalecente na economia.

\section{PALAVRAS-CHAVE}

endividamento, fragilidade financeira, atividade produtiva

\begin{abstract}
It is developed a post-keynesian dynamic macromodel of utilization and growth of productive capacity, in which the supply of credit-money is endogenous and firms' debt position is explicitly modeled. The interest rate is set by banks as a markup over the base rate, which is exogenously determined by the monetary authority. Over time, the banking markup varies in response to changes in the level of economic activity, which is measured by the utilization of productive capacity. In turn, firms' debt position varies according to the rates of profit, capital accumulation and interest. Regarding dynamics, it is shown the possibility of relating the stability properties of a system having the interest rate and the debt position by firms as state variables to the type of minskyan regime - hedge, speculative or Ponzi - which prevails among firms.
\end{abstract}

KEY WORDS indebtedness, financial fragility, productive activity

JEL Classification

$G 00, E / 2, E 22$ 


\section{INTRODUÇÃO}

O presente artigo elabora um modelo macrodinâmico pós-keynesiano de utilização e crescimento da capacidade produtiva, no qual a oferta de moeda de crédito é endógena e o grau de endividamento das firmas é explicitamente modelado. A taxa de juros é determinada pela aplicação de um markup sobre a taxa básica fixada exogenamente pela autoridade monetária. $\mathrm{O}$ mark-up bancário varia ao longo do tempo em função de mudanças no nível de atividade econômica, medido pelo grau de utilização da capacidade produtiva. $\mathrm{O}$ investimento das firmas depende positivamente da taxa de lucro da economia e negativamente da taxa de juros. Para viabilizar seu investimento planejado as firmas adquirem créditos no sistema financeiro e seu grau de endividamento, expresso como a relação entre a dívida e o estoque de capital físico, varia intertemporalmente em função das taxas de lucro, de investimento e de juros. A focalização nas variáveis de estado, taxa de juros e grau de endividamento permite analisar qualitativamente o comportamento dinâmico da economia, assim como relacionar as propriedades de estabilidade de sua solução de equilíbrio de longo prazo ao tipo de regime de financiamento - hedge, especulativo ou Ponzi - prevalecente no setor produtivo, conforme a taxonomia elaborada por Minsky (1975, 1982).

Em relação a modelos que procuraram formalizar a análise minskyana - por exemplo, os trabalhos de Taylor e O'Connell (1985) e de Foley (2001) -, o presente artigo se diferencia principalmente por dois aspectos. Em primeiro lugar, na forma como a determinação da taxa de juros é incorporada ao modelo no presente caso: admite-se que a oferta de moeda de crédito é endógena a uma taxa de juros que também é determinada, intertemporalmente, de forma endógena, via mark-up bancário variável ao longo do tempo, o qual incide sobre a taxa básica estabelecida exogenamente pela autoridade monetária. Em outros termos, embora se assuma que os bancos têm condições de atender plenamente à demanda por empréstimos à taxa de juros vigente, $\mathrm{O}$ mark-up bancário - e, assim, a taxa de concessão de empréstimos - é uma variável intertemporalmente endógena no modelo aqui desenvolvido, de maneira que a suposição de endogeneidade da oferta de moeda não se traduz em uma exogeneidade da taxa de juros ao longo do tempo. 
Em segundo lugar, o presente modelo se diferencia desses predecessores por colocar no centro da análise o processo de endividamento das firmas. No que tange especificamente às decisões de investir das firmas, Taylor e O'Connell (1985) procuram formalizar a análise minskyana da instabilidade financeira basicamente por meio de um fator de "exuberância" incluído na função investimento, o qual captaria a tendência potencialmente desestabilizadora de as firmas ampliarem acentuadamente o investimento durante períodos de boom econômico, sem estabelecer, porém, conexão formal desta tendência com o processo de endividamento das firmas como uma contrapartida provável dos níveis mais elevados de investimento.

Foley (2001), por sua vez, incorpora o endividamento em seu modelo macrodinâmico, mas o faz basicamente na forma de um processo de endividamento externo da economia em países em desenvolvimento. Não somente sua formalização da análise minskyana sobre a fragilidade financeira das firmas é bastante criativa, como ele inclusive discute explicitamente a dinâmica de seu endividamento, mas no plano da análise macrodinâmica este aspecto é incorporado exclusivamente via dívida externa. A razão para isto parece derivar do que Foley destaca como sendo um "aspecto curioso" que afetaria o modelo de Taylor e O'Connell e, por extensão, qualquer modelo de inspiração kaleckiana para uma economia fechada: se a relação entre a taxa de crescimento da economia, $g$, e a poupança a partir dos lucros, $s r$, onde $s$ é a propensão a poupar dos capitalistas e $r$ é a taxa de lucro, é dada, à la equação de Cambridge, por $g=s r$, assumir $s<1$, como parece razoável, forçosamente "impõe um regime minskyano de financiamento hedge, no qual $r>g$ ”. Segundo Foley, uma solução para esse dilema seria então a abertura da economia, garantindo assim taxas de crescimento superiores pela possibilidade de endividamento externo.

Nesse contexto, o presente modelo contempla, além dos vários aspectos produtivos e monetários mencionados acima, uma solução formal alternativa para o dilema sugerido por Foley, a qual indica que mesmo uma economia fechada pode vir a transitar entre os regimes hedge, especulativo e Ponzi. Em verdade, essa possibilidade é certamente compatível com a análise ori- 
ginal de Minsky $(1975,1982)$, posto que esta aparentemente não coloca como pré-requisito o endividamento externo como forma de transição entre aqueles diferentes regimes de financiamento.

O restante do artigo está organizado da seguinte forma. A seção 1 descreve a estrutura formal do modelo, enquanto a seção 2 analisa seu comportamento no curto prazo. A seção 3 estabelece as condições formais que definem os vários regimes minskyanos de financiamento e endividamento, ao passo que a seção 4 analisa o comportamento do modelo no longo prazo. A última seção reprisa os principais resultados derivados ao longo do artigo e tece considerações finais.

\section{ESTRUTURA DO MODELO}

Modela-se uma economia fechada e isenta de atividades fiscais por parte do governo. Um único bem é produzido, sendo ele utilizável tanto para consumo como para investimento. Apenas dois fatores homogêneos são utilizados em sua produção, capital e trabalho, os quais são combinados por meio de uma tecnologia caracterizada por coeficientes fixos. A hipótese de coeficientes fixos pode ser justificada com base numa independência da escolha de técnicas em relação ao preço relativo dos fatores ou em rigidezes tecnológicas na substituição entre os fatores de produção.

As firmas produzem de acordo com a demanda efetiva, sendo modelado aqui somente a situação em que esta é insuficiente para garantir a plena utilização da capacidade, de modo que as firmas operam com excesso de capacidade produtiva em termos de capital. ${ }^{1}$ Porém, nenhum excesso de mão-de-obra é empregado, posto que não existem contratos de trabalho de

I Segundo STEINDL (1952), as firmas oligopolistas operam com uma margem desejada de capacidade ociosa para responder a aumentos súbitos na demanda. Por um lado, a indivisibilidade e a durabilidade da planta e dos equipamentos impedem que a capacidade produtiva cresça pari passu ao crescimento do mercado. Por outro, isso cria uma barreira à entrada: a retençáo de excesso de capacidade permite confrontar eventuais recém-ingressantes por meio de uma elevação da oferta que reduza os preços. 
longa duração. As firmas também respondem pela acumulação de capital físico, sendo que seu investimento desejado pode ser descrito pela seguinte equação:

$$
g^{d}=\alpha+\beta r-\gamma i
$$

onde $\alpha, \beta$ e $\gamma$ são parâmetros positivos, $g^{d}$ é a acumulação desejada das firmas como proporção do estoque de capital físico, $K, r$ é a taxa de lucro total, definida como o fluxo total de lucros líquidos, $R$, dividido pelo estoque de capital, enquanto $i$ é a taxa de juros. Seguimos Robinson (1962), Kalecki (1971), Rowthorn (1981) e Dutt (1994) na suposição de que o investimento desejado guarda uma relação positiva com a taxa de lucro, posto que esta representa um indicador da lucratividade futura esperada e, além disso, facilita a obtenção de recursos externos. O último termo, por sua vez, captura o impacto (negativo) da taxa de juros, enquanto expressão do custo do capital financeiro, no que seguimos Dutt (1990-91, 1994).

A economia é habitada por duas classes sociais, capitalistas e trabalhadores. Seguindo a tradição pós-keynesiana inaugurada por Kalecki (1971), assume-se que essas classes adotam diferentes comportamentos de consumo e poupança. Os trabalhadores ofertam mão-de-obra e recebem apenas salários, os quais são totalmente gastos em consumo. Os trabalhadores estão sempre em excesso de oferta, com seu número crescendo a uma taxa exógena. Por sua vez, o conjunto dos capitalistas recebe sob a forma de lucros todo o excedente sobre os salários. Assim, a divisão funcional da renda entre trabalhadores e capitalistas é dada por:

$$
X=V L+r K
$$

onde $X$ é o nível de produto, $V$ é o salário real e $L$ é o nível de emprego. Porém, o agregado de lucros gerado pela economia é dividido entre capitalistas de dois setores, o produtivo e o financeiro, segundo a equação abaixo: 


$$
r K=r_{p} K+r_{f} K
$$

onde $r_{p}$ representa a fração da taxa de lucro total que cabe ao setor produtivo e $r_{f}$ a fração da taxa de lucro total que cabe ao setor financeiro, ambas expressas como fração do estoque de capital físico. Portanto, os lucros dos capitalistas financeiros representam uma dedução do fluxo agregado de lucros gerado pelo estoque de capital físico, numa proporção dada pelo estoque de dívida dos capitalistas produtivos junto com os financeiros e pela taxa de juros vigente. Enquanto os capitalistas produtivos poupam uma fração $s_{p}$ de sua parcela do total de lucros, os capitalistas financeiros poupam uma fração $s_{f}$ de sua parcela correspondente.

Empregando-se a equação (2), a taxa de lucro total da economia é dada por:

$$
r=(1-V a) u
$$

onde a é a relação trabalho-produto, $(1-V a)$ é a participação total dos lucros na renda e $u=X$ / $K$ é o grau de utilização da capacidade produtiva. Posto que se assume a constância da razão entre o produto potencial e o estoque de capital, pode-se então identificar o grau de utilização da capacidade produtiva com a relação produto-capital. ${ }^{2}$ Para efeito de focalização e redução da dimensionalidade do modelo, assume-se a constância da parcela total dos lucros na renda, de maneira que a taxa de lucro total somente pode variar em função de mudanças na utilização da capacidade produtiva. Dada a constância da relação trabalho-produto, a hipótese de que a parcela total de lucros seja constante implica, portanto, a constância do salário real.

2 Por simplicidade, o presente modelo não considera a ocorrência de mudanças tecnológicas. Para dois modelos macrodinâmicos pós-keynesianos de utilização e crescimento da capacidade produtiva que incorporam a ocorrência de inovaçôes tecnológicas poupadoras de trabalho, porém não formalizam o lado monetário, vide LIMA $(1999,2000)$. No primeiro, a taxa de inovação varia nãolinearmente com a parcela dos salários na renda. No segundo, com um espírito (neo-)schumpeteriano, a taxa de inovação depende não-linearmente da concentração de mercado. Em ambos, a nãolinearidade envolvida gera possíveis equilíbrios duplos e trajetórias cíclicas para as variáveis endógenas. 
Para tanto, assume-se que as variações no salário nominal e no nível de preços sejam nulas, de maneira que o modelo pode ser visto como desenvolvido exclusivamente em termos reais.

A taxa de juros, conforme sugerido por Rousseas (1985), é estabelecida pelos bancos com base em uma regra de mark-up. ${ }^{3}$ Especificamente, ela resulta da aplicação de um mark-up, $h>1$, sobre a taxa básica de juros, $i^{*}$, fixada exogenamente pela autoridade monetária:

$$
i=h i^{*}
$$

De uma perspectiva estilizada, assume-se que os bancos atuem como tomadores de preço e fixadores de quantidade no mercado de captação de fundos (cujo preço é definido em larga medida pela autoridade monetária), e como tomadores de quantidade (a demandada pelo setor produtivo, de acordo com suas decisóes de gasto) e fixadores de preço (com base no mark-up sobre o custo de captação) no mercado de concessão de crédito. Assim sendo, os bancos encontram-se em condições de atender à demanda de crédito do setor produtivo a um preço compatível com aquele que represente o mark-up pretendido sobre o custo de captação, de acordo com seus critérios de lucratividade, aversão ao risco e preferência pela liquidez. Por outro lado, procuram captar os recursos necessários e/ou gerar as reservas adequadas àquelas decisões de concessão de crédito.

Nesse sentido, o fato de os bancos estarem em condiçóes de satisfazer plenamente a demanda por empréstimos à taxa de juros vigente, seja por operarem com excesso de reservas ou por poderem recorrer a empréstimos da autoridade monetária, não significa que esta não possa influenciar o processo endógeno de criação de moeda de crédito em que se baseia o presente modelo. Aqui, porém, essa influência se dá em nível de preço, por meio da

3 Baseando-se na abordagem kaleckiana da fixação de preços em mercados oligopolizados, ROUSSEAS (1985) sugere que o preço dos empréstimos bancários é igualmente fixado por uma regra de mark-up. Mais especificamente, ele seria determinado pela aplicação de um mark-up sobre o custo dos fundos captados para realização desses empréstimos, com os custos fixos e de trabalho correspondentes sendo incluídos naquela margem. 
dosagem do juro básico, não de restrições quantitativas. ${ }^{4}$ Da mesma forma, a assumida endogeneidade da moeda de crédito não implica a impossibilidade de os próprios bancos influenciarem o acesso efetivo a ela. No modelo deste artigo, entretanto, essa influência é exercida em nível de restrições de acesso ao crédito via preço, não via quantidade. ${ }^{5}$

Os níveis da taxa básica, do mark-up bancário e, portanto, da taxa de juros, estão predeterminados num momento do tempo. Enquanto a taxa básica permanece constante ao longo do tempo, o mark-up bancário varia intertemporalmente de maneira endógena, de acordo com o nível de atividade econômica em relação a um nível exógeno de referência, ambos medidos pelo grau de utilização da capacidade produtiva:

$$
\text { It }=\theta_{1}\left(u-u_{r}\right)
$$

onde $\ell_{\ell}^{\S}$ é a taxa de variação do mark-up bancário, $d h / d t, \theta_{1}$ é um coeficiente de ajustamento positivo ou negativo e $u_{r}$ representa a utilização da capacidade correspondente ao nível de atividade econômica empregada como referência exógena pelos bancos na formação do mark-up. ${ }^{6} \mathrm{~A}$

4 Nesse sentido, o presente modelo adota o juro básico como referência do preço das reservas e também como uma proxy do custo de captação de recursos pelo sistema bancário. Admite-se que a autoridade monetária executa a política monetária exclusivamente via taxa básica; assim, no caso de uma eventual necessidade de liquidez por parte do sistema bancário, a autoridade monetária não atuará via restrições quantitativas, mas tão-somente via preço das reservas. Posto isso, e na ausência de alternativas de aplicação de seus recursos, aquela taxa estabelece a referência de remuneração para a riqueza rentista mantida no sistema bancário. Noutras palavras, a taxa básica também funciona como uma proxy dos custos de captação no sentido de que esses custos acompanham de perto as variaçóes da taxa básica, enquanto o mark-up bancário é que, de fato, atua como o elemento autônomo e variável endógena na formação da taxa de juros final.

5 Análises detalhadas das visões e controvérsias pós-keynesianas sobre a endogeneidade da oferta monetária podem ser encontradas em MEIRELLES (1995, 1998).

6 Uma especificação alternativa da dinâmica desses elementos do juro nominal pode ser encontrada em LIMA \& MEIRELLES (2003). Nele, o mark-up bancário varia negativamente com a taxa de lucro sobre o capital físico, com esta última servindo de medida da capacidade potencial de pagamento das firmas, enquanto a taxa básica é alterada positivamente pela autoridade monetária sempre que um excesso de demanda no mercado de bens não pode ser acomodado por uma variação na utilização da capacidade. Diferentemente do presente modelo, portanto, os comportamentos estático e dinâmico da economia são analisados para ambas as situações de utilização da capacidade, plena e abaixo dela, o que torna possível a multiplicidade de equilíbrios dinâmicos para as variáveis endógenas. Em LIMA \& MEIRELLES (2003), entretanto, a dinâmica do endividamento das firmas, assim como sua expressão em termos da taxonomia minskyana, não são modeladas, embora o seja a variabilidade intertemporal da parcela dos lucros totais na renda, o que é realizado via incorporação de uma dinâmica inflacionária governada por um mecanismo endógeno de conflito distributivo entre trabalhadores e capitalistas. 
negatividade do parâmetro caracteriza um comportamento anticíclico para o mark-up bancário, significando isso que um valor positivo (negativo) para o hiato entre a utilização efetiva e a utilização de referência provoca uma redução (elevação) do mark-up bancário. Por seu turno, a positividade do parâmetro define um comportamento pró-cíclico para o mark-up bancário, no qual um valor positivo (negativo) para o hiato entre a utilização efetiva e a de referência acarreta uma elevação (redução) do mark-up bancário. Colocando de outra forma, a natureza exógena da utilização de referência permite caracterizar o comportamento do mark-up bancário como sendo pró-ciclico (anticíclico) quando é positivo (negativo).

Sendo assim, um comportamento pró-cíclico para o mark-up bancário significa que o sistema bancário deseja se apropriar de uma parcela maior do faturamento produtivo à medida que o nível de atividade econômica - e, portanto, a taxa de lucro total da economia, conforme a equação (2) - se eleva. Por seu turno, um comportamento anticíclico significa que uma elevação na utilização da capacidade, ao ampliar a capacidade potencial das firmas de servir um dado nível de endividamento, reduz seu risco percebido de inadimplência e, com isso, provoca uma redução no mark-up bancário.

Em nível empírico, as evidências disponíveis dão suporte a ambos os comportamentos do mark-up bancário. No tocante à influência exercida pela inadimplência, por exemplo, um estudo contábil do Banco Central do Brasil (1999), a partir de uma amostra de grandes bancos privados nacionais no período Maio-Julho daquele ano, revelou que a inadimplência era o principal componente dos spreads das taxas de empréstimo, respondendo, em média, por $35 \%$ do valor destes - com porcentuais de $28 \%$ e $40 \%$, em média, para empréstimos aos tomadores pessoa física e pessoa jurídica, respectivamente. Por sua vez, no estudo de Aronovich (1994), com dados para a economia brasileira nos anos 1986-1992, o spread da taxa de capital de giro caracterizou-se por um sinal negativo e estatisticamente significante do coeficiente relativo à utilização da capacidade instalada. Já o estudo de Angbazo (1997) sobre o sistema bancário norte-americano detectou que a participação dos empréstimos inadimplentes nos empréstimos totais era uma variável explicativa significante dos spreads bancários, enquanto Saunders e Schumacher (2000), com base em dados para seis países euro- 
peus e os Estados Unidos nos anos 1988-1995, detectaram um impacto positivo significativo do risco de crédito percebido sobre as margens bancárias. Por outro lado, o estudo de Brock e Rojas-Suarez (2000), com dados de meados da década de 90 para alguns países sul-americanos, encontrou evidências de uma relação negativa entre inadimplência e spreads bancários. Entre os países analisados - Peru, Argentina, Bolívia, Chile e Colômbia -, apenas neste último foi detectada uma relação positiva entre índices de inadimplência e spreads. Na visão dos autores, uma racionalização possível para essa evidência seria que bancos com uma elevada fração de empréstimos ruins podem eventualmente reduzir seus spreads na tentativa de atenuar os problemas daí oriundos.

O grupo de capitalistas financeiros é composto de rentistas e banqueiros, ambos tendo a mesma propensão a poupar. Os ativos retidos pelos rentistas são constituídos pelos certificados de depósitos bancário e os créditos emitidos ao setor produtivo representam os ativos mantidos em carteira pelos banqueiros. Assume-se que a riqueza rentista não captada pelos bancos permanece ociosa e sobre ela não incide qualquer rendimento, de maneira que a renda do setor financeiro como um todo, incluindo banqueiros e rentistas, é exatamente a contraparte do serviço da dívida do setor produtivo. ${ }^{7}$ Como proporção do estoque de capital físico, o grau de endividamento do setor produtivo é dado por:

$$
\delta=\frac{D}{K}
$$

7 Noutros termos, o presente artigo não pretende tratar diretamente da maneira como a renda financeira se divide entre rentistas e banqueiros. Embora diferenças entre o montante de recursos captados, pelos bancos, com os rentistas e o montante emprestados pelos banqueiros ao setor produtivo em um dado período se refletirão na forma como a renda financeira se dividirá entre rentistas e banqueiros, não afetarão, porém, o total dessa renda. Se os bancos captarem mais que o necessário, parcela da renda auferida com o mark-up bancário será repassada aos rentistas para remunerar o excesso de captação; caso contrário, parcela adicional de suas próprias reservas será utilizada e os bancos receberão uma maior parte da renda financeira. Porém, os detalhes deste processo e a forma da divisão dessa renda não são focalizados pelo presente modelo e, dadas as hipóteses assumidas, também não afetam os seus resultados, posto que não modificam o total da renda financeira e, como assumido acima, a propensão a poupar dos capitalistas financeiros é a mesma, independente de sua classificação como rentistas ou banqueiros. 
onde $D$ representa a dívida do setor produtivo para com o setor financeiro. Portanto, a variação do grau de endividamento ao longo do tempo pode ser obtida pela diferenciação da equação (7):

$$
\frac{d \delta}{d t}=\delta=\frac{B^{\mathrm{X}}}{K}-\delta g
$$

onde $\mathbb{Q}^{\&}$ é a variação da dívida ao longo do tempo e, assumindo-se que o capital não está sujeito a depreciação, $g$ é a taxa de crescimento do estoque de capital e, portanto, a taxa de crescimento dessa economia que produz um único bem.

\section{COMPORTAMENTO DO MODELO NO CURTO PRAZO}

O curto prazo é definido como sendo o período de tempo em que a taxa de juros, $i$, o estoque de dívida do setor produtivo, $D$, o estoque de capital físico, $K$, e, portanto, o grau de de endividamento das firmas, $\delta$, estão todos predeterminados. Posto que as firmas produzem de acordo com a demanda efetiva sob condições de excesso de capacidade, a equalização macroeconômica entre oferta e demanda é gerada por meio de variaçóes no nível de produto e, portanto, na utilização da capacidade produtiva. Em termos formais, a aludida equalização no mercado de bens pode ser assim representada:

$$
[(1-V a) X-i D]+i D+V a X=\left(1-s_{p}\right)[(1-V a) X-i D]+\left(1-s_{f}\right) i D+V a X+I
$$

onde $I$ é o nível de investimento das firmas e $i D$ é o serviço de sua dívida acumulada, o qual representa, portanto, a renda do setor financeiro. Os três primeiros termos do lado direito da equação (9), por seu turno, representam, respectivamente, os níveis de consumo dos capitalistas produtivos, dos capitalistas financeiros e dos trabalhadores, conforme assumido anteriormente em termos de comportamento de poupança. Como proporção do estoque de capital, portanto, a poupança agregada, $g^{s}$, é dada por: 


$$
g^{s}=s_{p} r+\left(s_{f}-s_{p}\right) i \delta
$$

A equação acima indica os possíveis efeitos da diferença de padrão de consumo dos capitalistas do setor produtivo e do setor financeiro no equilíbrio de curto prazo da atividade produtiva e no comportamento dinâmico da economia. ${ }^{8}$ Como, porém, o principal objetivo do presente modelo é analisar a dinâmica do endividamento do setor produtivo e sua relação com os regimes minskyanos de financiamento, esses possíveis efeitos serão desconsiderados. Em termos formais, assume-se uma mesma propensão a poupar para o conjunto dos capitalistas, $s=s_{f}=s_{p}$, o que resulta na versão original da chamada equação de Cambridge:

$$
g^{s}=s r
$$

Quando normalizada pelo estoque de capital e simplificada, a condição de equilíbrio de curto prazo da atividade produtiva, equação (9), torna-se então:

$$
s(1-V a) u=g^{d}
$$

Portanto, a equação (12) é uma representação alternativa da condição de equilíbrio de curto prazo da atividade produtiva, expressa agora em termos de igualdade entre poupança e investimento, conforme as equações (4) e (11). A existência de capacidade ociosa permite que as firmas concretizem seus planos de acumulação de capital, com a utilização da capacidade ajustando-se então para eliminar eventuais excessos de demanda ou de oferta. Substituindo as expressões para o investimento desejado das firmas e para a taxa de lucro total - equações (1) e (4), respectivamente -, na equação (12), pode-se obter a solução de equilíbrio de curto prazo de $u$, dados o nível de $i$ e os parâmetros do modelo:

8 DUTT $(1989,1992)$ extrai diversas conclusões dinâmicas de um modelo que diferencia as propensões a poupar de capitalistas e rentistas, mas trabalha com o conceito de riqueza rentista, não com o grau de endividamento das firmas. Tal riqueza cresce ao longo do tempo em função da taxa de juros (exógena) que incide sobre a mesma e em função da propensão a poupar dos rentistas. 


$$
u^{*}=\frac{(\alpha-\gamma i)}{(s-\beta)(1-V a)}
$$

Em termos de estabilidade, assume-se um mecanismo de ajuste keynesiano de acordo com o qual a utilização da capacidade varia positivamente com qualquer excesso de demanda no mercado de bens:

$$
\iota \&=d u / d t=\phi\left[g^{d}-g^{s}\right]=\phi[\alpha+\beta(1-V a) u-\gamma i-s(1-V a) u]
$$

onde $\phi>0$ é a velocidade (constante) de ajustamento da utilização da capacidade produtiva. Portanto, a estabilidade do valor de equilíbrio de curto prazo de $u$ requer $d \downarrow \& d u<0$, ou seja, $s>\beta$. Em palavras, a estabi lidade de $u^{*}$ requer que a poupança agregada seja mais sensível que o investimento desejado a variações na utilização da capacidade, o que se assume no que segue. Dado que a parcela total dos lucros na renda está restrita ao intervalo $[0,1]$, assume-se ainda a positividade do numerador da equação (13), ou seja, $i<\alpha / \gamma$, o que garante a ocorrência de somente valores positivos para $u^{*}$.

O valor de equilíbrio de curto prazo da taxa de lucro total da economia é obtido pela substituição da equação (13) na equação (4), o que gera:

$$
r^{*}=\frac{(\alpha-\gamma i)}{(s-\beta)}
$$

Por sua vez, o equilíbrio de curto prazo da taxa de crescimento da economia é obtido pela substituição da equação (15), seja na equação (1) ou na equação (11), o que de qualquer forma gera:

$$
g^{*}=\frac{s(\alpha-\gamma i)}{(s-\beta)}
$$


Dado que a estabilidade do equilíbrio de curto prazo de $u^{*}$ requer $s>\beta$ e, portanto, que a positividade de $u^{*}$ requer $i<\alpha / \gamma$, as equações (13), (15) e (16) indicam, respectivamente, que $d u^{*} / d i=u_{i}^{*}<0, d r^{*} / d i=r_{i}^{*}<0$ e $d g^{*} / d i=g_{i}^{*}<0$. Em palavras, um aumento na taxa de juros, ao afetar negativamente o investimento das firmas, reduz os valores de equilíbrio de curto prazo da utilização da capacidade produtiva e das taxas de lucro total e de crescimento da economia. ${ }^{9}$

\section{ENDIVIDAMENTO E REGIMES DE FINANCIAMENTO DO INVESTIMENTO}

A partir da identidade de fluxo de caixa para as firmas apresentada abaixo é possível obter tanto uma equação para a variação de sua dívida ao longo do tempo (FOLEY, 2001) como colocar a taxonomia minskyana em uma forma adequada aos propósitos do presente modelo:

$$
R+B \equiv I+F
$$

onde $R$ representa as receitas líquidas de operação das firmas, $B$ os novos empréstimos, $I$ o investimento e $F$ o serviço da dívida contraída pelas fir-

9 Como pode ser checado, os sinais dessas derivadas poderiam se tornar positivos caso se tivesse admitido diferentes propensóes a poupar para os dois grupos de capitalistas. Para tanto, basta substituir a expressão para a taxa de lucro total, equação (4), nas expressões para a poupança agregada completa, equação (10), e para o investimento desejado, equação (1), igualar as expressões resultantes e então resolver para $u, r$ e $g$. Agora, o equilíbrio de curto prazo destas variáveis dependeria não apenas de $i$ e parâmetros, mas também do grau de endividamento do setor produtivo, e sua estabilidade requereria $s_{p}>\beta$. Os sinais de $\partial u^{*} / \partial i$ e $\partial u^{*} / \partial \delta$, por exemplo, dependeriam do valor relativo das propensões a poupar dos capitalistas, com $s_{p}<s_{f}$ tornando ambos negativos. Por seu turno, $s_{p}>s_{f}$ poderia, dependendo de quão elevada fosse esta diferença, tornar positivo o sinal de $\partial u^{*} / \partial i$, enquanto geraria um sinal positivo para $\partial u^{*} / \partial \delta$. Como pode ser intuído a partir da equação (9), o efeito final sobre a utilização da capacidade dessas variaçóes na taxa de juros e no grau de endividamento dependeria de seu impacto sobre o investimento e o consumo dos capitalistas - ou seja, sobre a demanda efetiva. Consideraçóes semelhantes se aplicariam, mutatis mutandis, aos sinais das derivadas parciais das taxas de lucro total e de crescimento da economia. 
mas anteriormente. $\mathrm{O}$ valor dos novos empréstimos, $B$, representa a variação da dívida ao longo do tempo, de forma que:

$$
B^{\&}=B=I+F-R
$$

Uma vez que os investimentos das firmas são acréscimos ao seu estoque de capital prévio, com $g=I / K$, que $R$ é o lucro líquido total na economia, correspondendo, portanto, a $(X-V L)$, de forma que a taxa de lucro total também pode ser expressa como $r=R / K$, conforme a equação $(2)$, e considerando, por fim, que a taxa de juros pode ser contabilizada como a razão do serviço da dívida pelo seu estoque, o que resulta em $i=F / D$, pode-se obter a seguinte equação para a variação do endividamento das firmas ao longo do tempo:

$$
\not \&=(g-r) K+i D
$$

A partir da identidade de fluxo de caixa das firmas também é possível formalizar a taxonomia minskyana da seguinte forma:

Hedge: $R \geq I+F$ ou $B \leq 0$

Especulativo: $R<I+F$ ou $I>B>0$

Ponzi: $R \leq F$ ou $B \geq I$

Empregando-se as definições anteriores de taxas de crescimento, de lucro e de juros, a definição de grau de endividamento como proporção do esto ${ }^{-}$ que de capital e tendo em conta que $r \equiv r_{p}+r_{f}=r_{p}+i \delta$, ${ }^{10}$ a taxanomia minskyana apresentada acima pode ser representada em qualquer das duas formas indicadas na tabela a seguir:

10 Observe que esta identidade não só é coerente com a equação (3), como também está implícita na equação (9), do equilíbrio entre oferta e demanda no mercado de bens. 
Tipo de financiamento

Hedge

$$
r-i \delta \geq g \quad r_{p} \geq g
$$

Especulativo

$$
r-i \delta<g \quad r_{p}<g
$$

Ponzi

$r-i \delta \leq 0$

$r_{p} \leq 0$

Portanto, o indicador adequado do tipo de regime de financiamento das firmas é o valor da taxa de lucro do setor produtivo e sua comparação com a taxa de crescimento da economia, uma abordagem distinta da proposta por Foley (2001), o qual sugere empregar a taxa de lucro de toda a economia nesta comparação. Deve-se também observar que a presente abordagem deixa claro que o lucro do setor produtivo é uma função não só do fluxo de lucro de toda a economia, incorporado via taxa de lucro, $r$, mas também do serviço da dívida, $i \delta$, o qual reflete os efeitos da taxa de juros e do estoque de endividamento passado, indicando que a demarcação dos regimes minskyanos é melhor representada no espaço $(i, \delta)$, como se verá a seguir, e não no espaço $(i, g)$, como sugere Foley (2001).

Com efeito, a combinação das inequações derivadas acima com as equações (15) e (16), para $r^{*}$ e $g^{*}$, respectivamente, permite traçar linhas demarcatórias dos diferentes regimes de financiamento no espaço :

$$
\begin{aligned}
& \delta_{h-e}=\frac{(1-s) \alpha}{(s-\beta)} \frac{1}{i}-\frac{(1-s) \gamma}{(s-\beta)} \\
& \delta_{e-p}=\frac{\alpha}{(s-\beta)} \frac{1}{i}-\frac{\gamma}{(s-\beta)}
\end{aligned}
$$

onde $\delta_{h-e}$ e $\delta_{e-p}$ indicam os níveis de grau de endividamento correspondentes às transições de hedge para especulativo e de especulativo para Ponzi, respectivamente, para cada nível de de juros selecionado. Estas linhas demarcatórias são ilustradas na Figura 1, indicando que combinações de taxas de juros elevadas e maiores graus de endividamento correspondem ao 
regime Ponzi de financiamento, enquanto combinações destas variáveis com pelo menos uma delas a um baixo nível de valor absoluto indicam a predominância do regime hedge.

\section{COMPORTAMENTO DO MODELO NO LONGO PRAZO}

Para a análise de longo prazo, assume-se que os valores de equilíbrio de curto prazo da variável endógena $u$ e, como conseqüência, também os valores das variáveis $r$ e $g$, são sempre alcançados. A economia move-se ao longo do tempo devido a variações no estoque de capital, na taxa de juros e no nível de endividamento. Sendo assim, uma forma de acompanhar a dinâmica do sistema é examinar o comportamento ao longo do tempo de suas variáveis de estado, a saber, a taxa de juros e o grau de endividamento. Empregando as equaçóes (5) e (6) para as variações da taxa de juros, e as equações (8) e (19) para as mudanças no grau de endividamento, tem-se o seguinte sistema autônomo bidimensional de equações diferenciais:

$$
\begin{aligned}
& \& d i / d t=i^{*} \theta_{1}\left(u-u_{r}\right) \\
& \&=d \delta / d t=(g-r)+\delta(i-g)
\end{aligned}
$$

A matriz Jacobiana associada ao sistema dinâmico acima é a seguinte:

$$
\begin{aligned}
& J_{11}=\partial \partial i=i^{*} \theta_{1} u_{i}^{*} \\
& J_{12}=\partial \delta \partial=0 \\
& J_{21}=\partial \delta^{\&} \partial \partial=(1-\delta) g_{i}^{*}+\delta-r_{i}^{*}=\frac{\gamma(1-s)+\delta(\gamma s+s-\beta)}{(s-\beta)}>0 \\
& J_{22}=\partial \delta^{\prime} \partial \partial=i-g
\end{aligned}
$$


Analisemos os sinais dos elementos dessa matriz Jacobiana. Como $u_{i}^{*}<0$, o sinal de $J_{11}$ será negativo (positivo) no caso do mark-up bancário comportar-se de maneira pró-cíclica (anticíclica), ou seja, no caso de $\theta_{1}>0$ $\left(\theta_{1}<0\right)$. Na situação pró-cíclica, os bancos desejam uma maior parcela do faturamento produtivo à medida que a economia passa a ter níveis de atividade maiores e tenda a se aproximar de $u_{r}$. No segundo caso, uma elevação no grau de utilização da capacidade produtiva, ao ampliar a capacidade potencial das firmas de servir suas obrigações financeiras, reduz seu risco percebido de inadimplência e, com isso, provoca uma redução no mark-up bancário. Por seu turno, $J_{12}=0$ indica que a taxa de variação no mark-up bancário não depende diretamente do grau de endividamento das firmas. Já $J_{21}>0$ simplesmente indica que a taxa de variação do grau de endividamento aumenta com o aumento da taxa de juros, tanto porque este último aumento eleva a variação da dívida das firmas ao longo do tempo, $\mathbb{Q}$, como também porque ele reduz as taxas de lucro total e de crescimento da economia. O sinal de $J_{22}$, no entanto, é claramente ambíguo, já que depende dos níveis relativos da taxa de juros e da taxa de crescimento. A mudança do sinal deste termo ocorre quando a fronteira $i-g=0$ é atravessada. Empregando-se a equação (16) pode-se determinar o valor de correspondente a esta fronteira:

$$
i_{i=g^{*}}=\frac{\alpha s}{(s-\beta+\gamma s)}
$$

A localização desta fronteira no espaço $(i, \delta)$ pode ser feita comparando-se o valor de taxa de juros que promove $i=g$ com os valores de taxa de juros correspondentes à transição entre os diferentes regimes de financiamento. Os valores de taxa de juros destas transições, para um nível de $\delta=1$, podem ser obtidos pelas equaçóes (26) e (27) e encontram-se representados na Figura 1. Vale observar que $\delta=1$ corresponde à situação em que a dívida das firmas é igual ao valor total do estoque de capital. 
FIGURA 1 - REGIMES MINSKYANOS NO ESPAÇO (TAXA DE JUROS $i$ X GRAU DE ENDIVIDAMENTO $\delta$ )

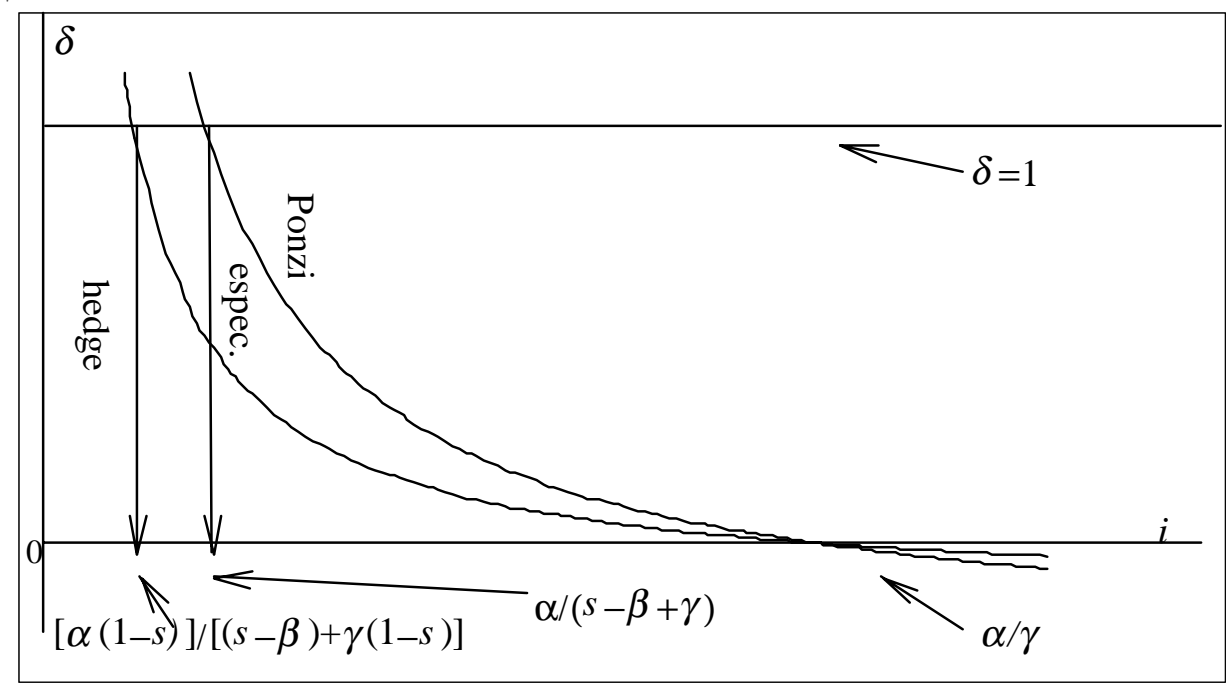

Comparando-se os valores de $\left[i_{i=g^{*}}=\alpha s /(s-\beta+\gamma s)\right] \quad \mathrm{e}$ $\left[i_{\delta_{e-p}=1}=\alpha /(s-\beta+\gamma)\right]$, pode-se concluir que a fronteira representada pela equação (34) encontra-se necessariamente à esquerda da região Ponzi, pois sua localização à direita daquela região exigiria valores de $s$ e $\beta(s<\beta$ ou $s>1$ ) incompatíveis com as restrições impostas aos parâmetros do modelo para garantir a positividade e estabilidade do valor de equilíbrio de curto prazo da utilização da capacidade produtiva $(0<\beta<s \leq 1)$.

A mesma comparação feita agora com $i_{\delta_{h-e}=1}=[\alpha(1-s)] /[(s-\beta)+\gamma(1-s)]$ indica que esta fronteira também estará à esquerda da região especulativa se $s<0,5$, e poderá estar à direita de uma pequena parcela da parte superior da região especulativa se e somente se se $s>0,5$. Sendo assim, a localização exata da fronteira dependerá da especificação do valor da propensão a poupar do conjunto dos capitalistas, mas a localização desta fronteira está de toda forma circunscrita a uma região relativamente restrita do espaço $(i, \delta)$, como ilustrado na Figura 2.

A Figura 2 mostra que para valores de se $i<g$ vigora o regime de financiamento hedge mesmo para níveis muito elevados do grau de endividamento. Para que valores de juros menores que a taxa de cresci- 
mento conduzam a um regime especulativo é necessário que a economia se caracterize por uma propensão a poupar dos capitalistas muito elevada. Já para valores de $i>g$ o predomínio do regime Ponzi é nítido e o mesmo só não ocorrerá no caso de a economia encontrar-se em uma situação de grau de endividamento suficientemente baixo.

FIGURA 2 - LOCALIZAÇÃO DA FRONTEIRA $i-g=0$

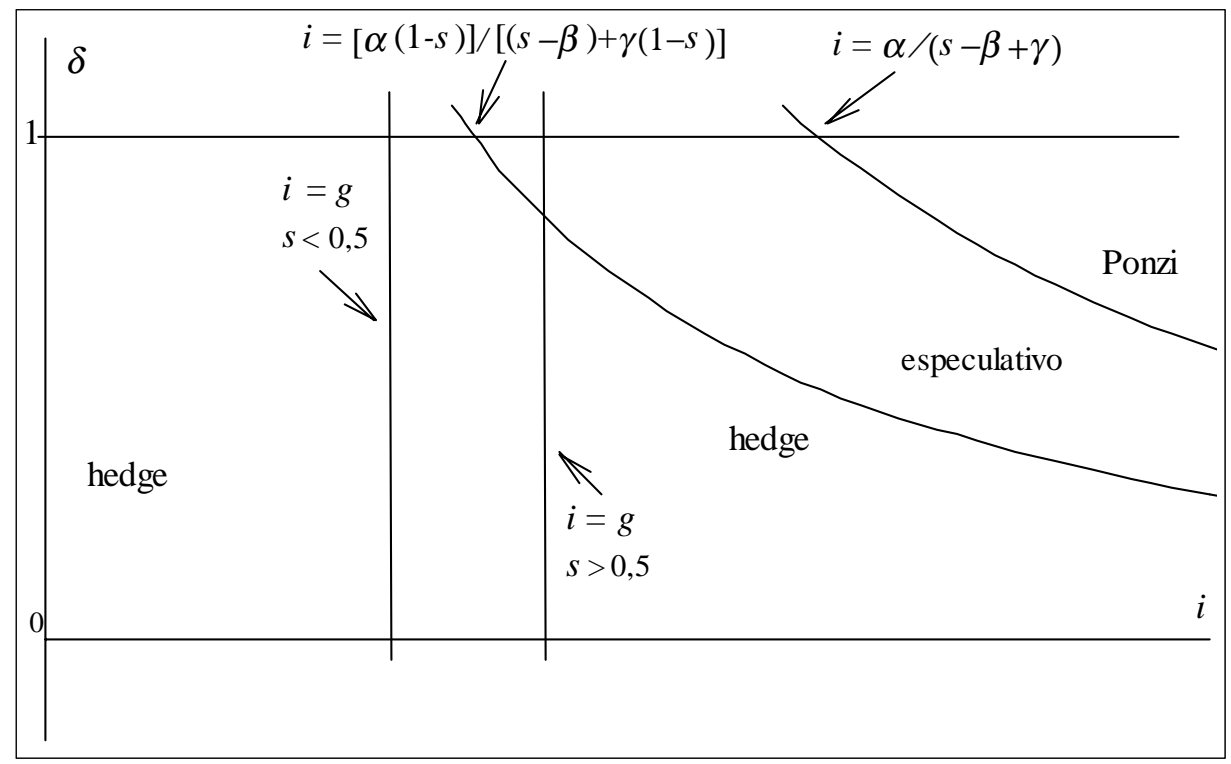

Como visto acima, o sinal de $J_{11}$ será negativo no caso do mark-up bancário ser pró-cíclico $\left(\theta_{1}>0\right)$. Admitindo que a economia encontre-se em uma situação em que $i<g$ e, portanto, $J_{22}<0$, o traço da matriz Jacobiana será negativo e seu determinante será positivo, com o que o equilíbrio de longo prazo definido por $\&=0$ será estável, como ilustrado na Figura 3. A inclinação da isolinha $\delta^{\&}=0$, dada por $-\left(J_{21} / J_{22}\right)$, é positiva. Dado que o sinal de $\partial \& \& \partial \delta$ é negativo, $\delta^{\&}$ cai conforme $\delta$ sobe, de maneira que seu sinal é positivo (negativo) à direita (esquerda) da respectiva isolinha, explicando, assim, a direção das setas verticais. Por sua vez, a nulidade de $\partial \notin \partial \delta$ implica que a isolinha 0 é uma reta vertical. Como o sinal de $\partial \notin \partial i$ é negativo, $f$ cai conforme $i$ sobe, seu sinal sendo positivo (negativo) à esquerda (direita) da respectiva isolinha, o que explica a direção das setas horizontais. Sendo assim, o equilíbrio de longo prazo, $E$, é um nódu- 
lo estável. Para as mais diversas combinações de $i$ e $\delta$, garantido que $i<$ $g$, essa economia hedge se movimentaria no longo prazo em direção a um equilíbrio no qual o grau de endividamento acabaria se estabilizando.

Caso, porém, o mark-up bancário seja anticíclico, tornando positivo o sinal de $J_{11}$, o determinante da Jacobiana será negativo, fazendo com que o equilíbrio definido por $\&=0$ seja instável, como ilustrado na Figura 4 . A nulidade de $\partial \notin \partial \delta$ significa que a isolinha 0 é uma reta vertical. Como o sinal de $\partial \& \partial i$ é positivo, $\mathfrak{e}$ sobe conforme $i$ sobe, daí a direção das setas horizontais. Por sua vez, a inclinação da isolinha $\&^{\mathbb{E}=0} 0$, dada por $-\left(J_{21} / J_{22}\right)$, é positiva. Posto que o sinal de $\partial \&^{\&} \partial i$ é positivo, $\mathbb{\&}^{\&}$ sobe conforme $i$ sobe, de forma que seu sinal é positivo (negativo) à direita (esquerda) da respectiva isolinha, o que explica a direção das setas verticais. Assim sendo, o equilíbrio de longo prazo, $E$, é um ponto de sela, com a separatriz correspondente sendo a própria isolinha 0 .

\section{FIGURA 3 - EQUILÍBRIO ESTÁVEL (NÓDULO) EM REGIME DE FINANCIAMENTO HEDGE}

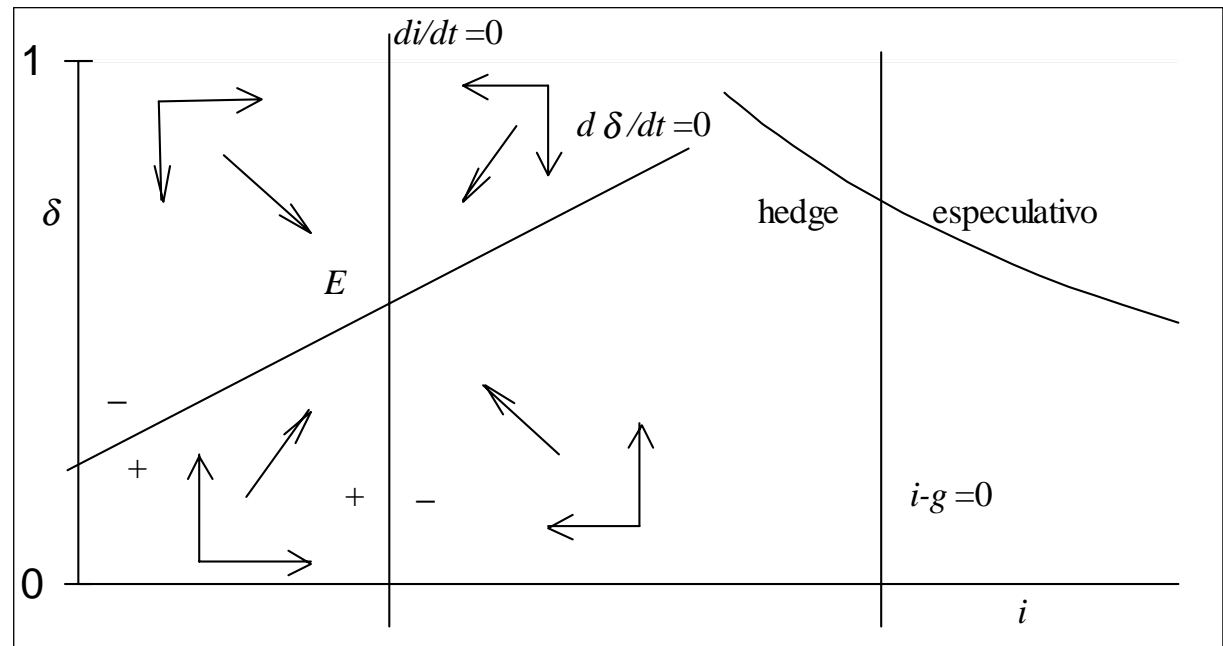


FIGURA 4 - EQUILÍBRIO INSTÁVEL (PONTO DE SELA) EM REGIME DE FINANCIAMENTO HEDGE

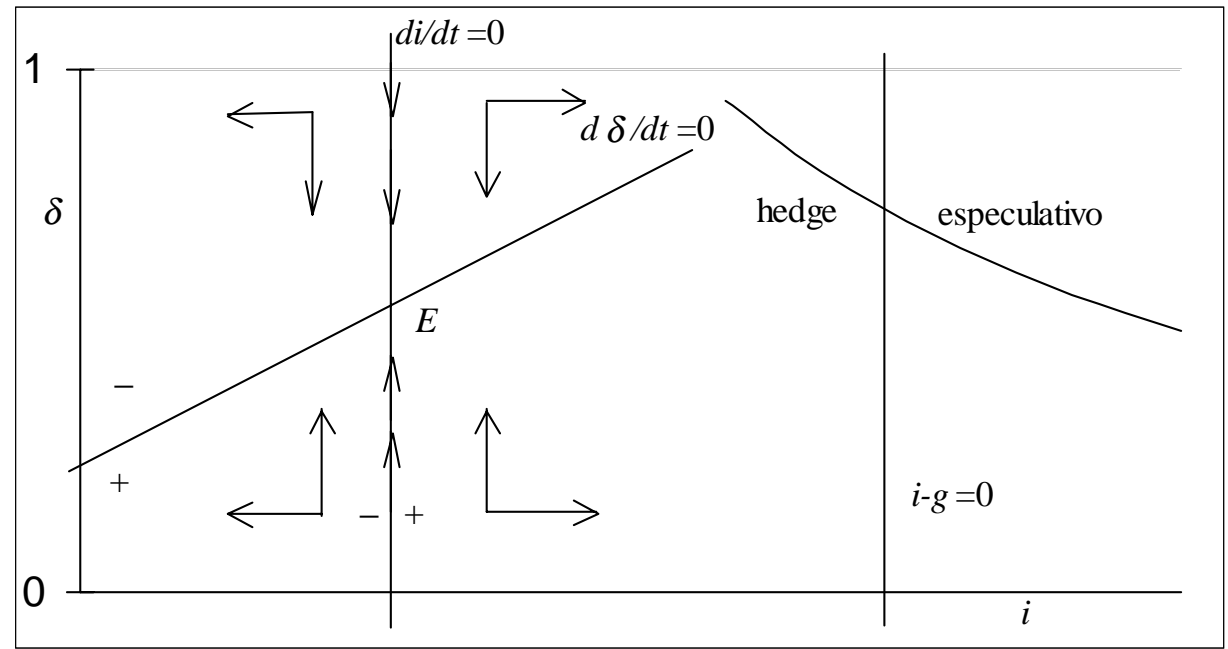

Como o termo $J_{22}$ da matriz Jacobiana depende dos níveis de $i$ e $g$, analisemos mais detalhadamente a especificação de taxa de juros utilizada no presente modelo. Integrando a equação (6) e substituindo-a na equação (5), obtém-se:

$$
i(t)=i^{*} \theta_{0}+i^{*} \theta_{1} \int_{t}\left(u-u_{r}\right) d t
$$

onde $\theta_{0}$ representa um termo constante na formação do mark-up bancário. Portanto, a taxa de juros seria formada por um termo constante, $i^{*} \theta_{0}$, e outro variável, oscilando este último segundo a diferença $\left(u-u_{r}\right)$. No ponto de equilíbrio esta diferença desaparece e a taxa de juros seria formada basicamente pelos seu elementos constantes. Admita-se que em uma situação como a representada pela Figura 3 a Autoridade Monetária decida aumentar a taxa básica, $i^{*}$, e/ou o sistema bancário decida aumentar o componente constante de seu mark-up. Caso este aumento seja suficientemente grande ele poderá inverter o sinal do elemento $J_{22}$, lançando a economia na direção da região Ponzi. Observe que, dados os parâmetros da função investimento, um aumento de $i^{*}$ e/ou $\theta_{0}$ implica aproximação pela esquerda da fronteira $i-g=0$ e, eventualmente, sua ultrapassagem, como pode ser visto pela equação (36): 


$$
i-g=\frac{(s-\beta+\gamma s) \theta_{0} i^{*}}{(s-\beta)}+\frac{(s-\beta+\gamma s) \theta_{1} i^{*}}{(s-\beta)} \int_{t}\left(u-u_{r}\right) d t-\frac{\alpha s}{(s-\beta)}
$$

Se a economia ultrapassar aquela fronteira e atingir ou aproximar-se bastante da região Ponzi, o sinal de $J_{22}$ tornar-se-á positivo e a solução de equilíbrio definida por $\&=0$ será necessariamente instável, não importando o comportamento do mark-up bancário e, portanto, o sinal de $J_{11}$. Vale observar que isto ocorrerá mesmo para baixos graus de endividamento, ou seja, mesmo que a economia se encontre próxima ou em uma situação hedge, desde que os valores de taxas de juros sejam elevados e $i>g$.

Com $J_{11}$ sendo negativo e $J_{22}$ positivo, o determinante da matriz Jacobiana torna-se negativo, caracterizando o equilíbrio de longo prazo definido por $\&=0$ como um ponto de sela, conforme ilustrado na Figura 5. A inclinação da isolinha $\&=0$, dada por $-\left(J_{21} / J_{22}\right)$, é negativa. Dado que o sinal de $\partial \delta^{\&} \partial \delta$ é positivo, $\delta^{\&}$ sobe conforme $\delta$ sobe, de maneira que seu sinal é negativo (positivo) à esquerda (direita) da respectiva isolinha, explicando assim a direção das setas verticais. Por sua vez, a nulidade de $\partial \& \partial \delta$ implica que a isolinha é uma reta vertical. Como o sinal de $\partial \& \partial i$ é negativo, $\delta$ cai conforme $i$ sobe, seu sinal sendo então positivo (negativo) à esquerda (direita) da respectiva isolinha, o que explica a direção das setas horizontais. Sendo assim, o equilíbrio de longo prazo, E, é um ponto de sela, com a separatriz correspondente sendo a própria isolinha .

Com os sinais de $J_{11}$ e $J_{22}$ sendo positivos, por sua vez, o determinante da Jacobiana torna-se positivo, porém o mesmo ocorre com seu traço, caracterizando o equilíbrio de longo prazo como instável, conforme ilustrado na Figura 6. A inclinação da isolinha $\&^{\&}=0$, dada por $-\left(J_{21} / J_{22}\right)$, é novamente negativa. Dado que o sinal de $\partial \& \psi d \partial \delta$ é positivo, $\delta^{\&}$ sobe conforme $\delta$ sobe, de maneira que seu sinal é negativo (positivo) à esquerda (direita) da respectiva isolinha, explicando a direção das setas verticais. Como nas situações anteriores, a nulidade de $\partial \& \partial \delta$ implica que a isolinha 0 é uma reta vertical. Como o sinal de $\partial i k \partial i$ é positivo, $\&$ sobe conforme $i$ sobe, com seu sinal sendo positivo (negativo) à direita (esquerda) da res- 
pectiva isolinha, o que explica a direção das setas horizontais. Portanto, o equilíbrio de longo prazo, $E$, é um nódulo instável.

FIGURA 5 - EQUILÍBRIO INSTÁVEL (PONTO DE SELA) EM REGIME DE FINANCLAMENTO PONZI

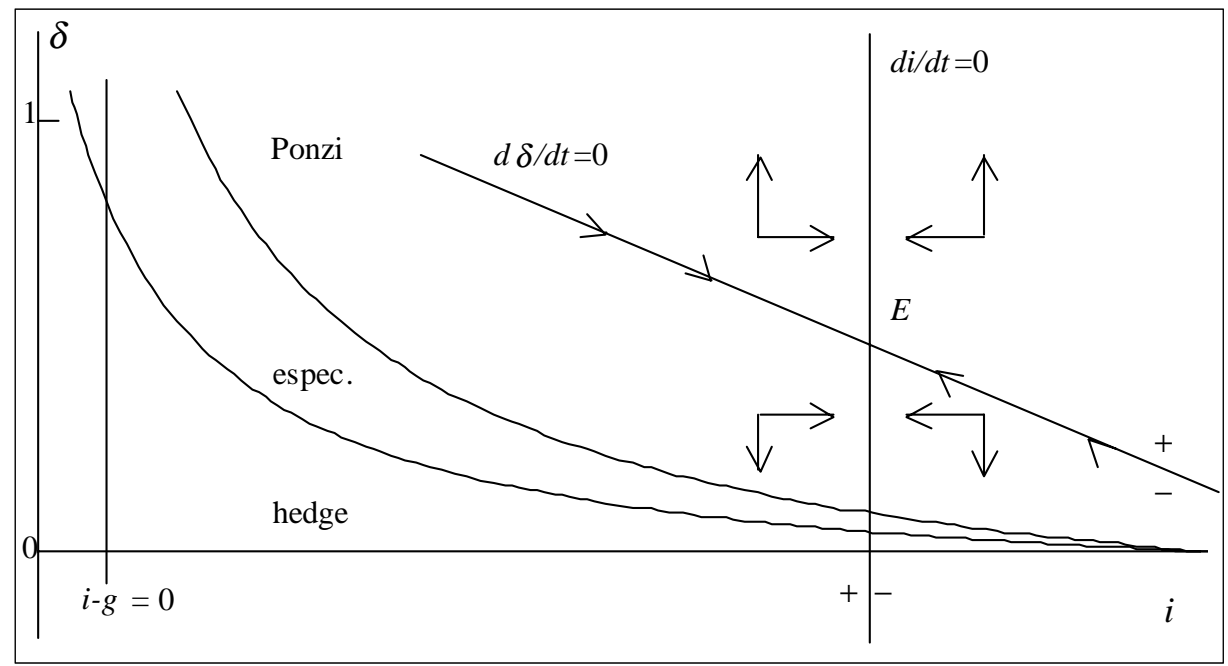

FIGURA 6 - EQUILÍBRIO INSTÁVEL (NÓDULO) EM REGIME DE FINANCIAMENTO PONZI

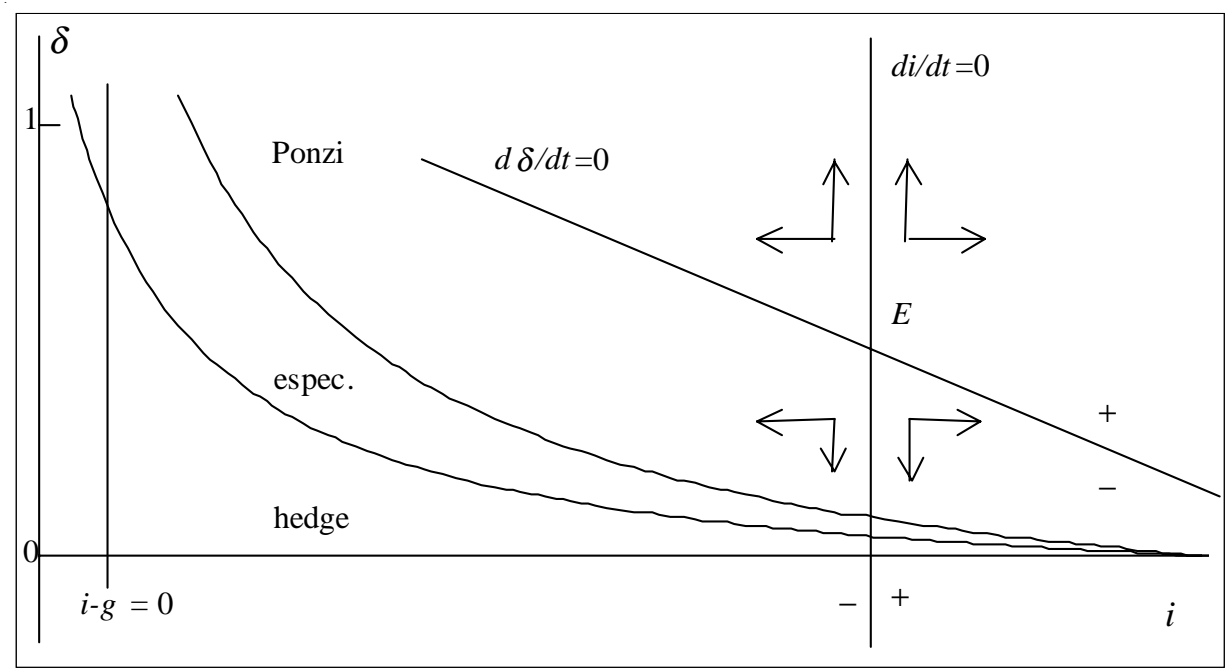




\section{REPRISE}

O presente artigo elaborou um modelo macrodinâmico pós-keynesiano de utilização e crescimento da capacidade produtiva, no qual a oferta monetária é endógena e a dinâmica do endividamento do setor produtivo é explicitamente formalizada. Em relação a modelos que formalizam a abordagem minskyana - particularmente Taylor e O'Connell (1985) e Foley (2001) - o presente artigo se diferencia pela suposição de que a oferta de moeda é endógena a uma taxa de juros que também é determinada, ao menos parcialmente, de maneira endógena, dada a sensibilidade do markup bancário ao ritmo da atividade produtiva, e pela colocação no centro da análise do endividamento das firmas. Em especial, o modelo macrodinâmico ora elaborado apresentou uma solução formal alternativa para o dilema analítico mencionado por Foley (2001), mostrando que mesmo uma economia fechada pode transitar entre os regimes de financiamento hedge, especulativo e Ponzi, algo bastante compatível com a análise original de Minsky (1975, 1982).

As decisões de produção das firmas são determinadas pelo nível de demanda efetiva, tendo sido modelada apenas a situação em que este nível não é suficiente para garantir a plena utilização da capacidade produtiva. As decisões de investimento do setor produtivo, por sua vez, dependem positivamente da taxa de lucro da economia e negativamente da taxa de juros, sendo viabilizadas pela aquisição de créditos no sistema financeiro. Sendo assim, o grau de endividamento do setor produtivo, expresso como a relação entre o endividamento assim contraído e o estoque de capital físico, varia intertemporalmente em função das taxas de lucro, de investimento e de juros. Nesse contexto, os lucros dos capitalistas financeiros representam uma dedução do fluxo total de lucros gerado pela utilização do estoque de capital físico, numa proporção dada pelo estoque de endividamento dos capitalistas produtivos e pela taxa de juros vigente.

Por seu turno, a taxa de juros resulta da aplicação, pelos bancos, de $u m$ mark-up sobre a taxa básica fixada exogenamente pela autoridade monetária. Assim sendo, o fato de os bancos estarem em condições de satisfazer plenamente a demanda por empréstimos à taxa de juros vigente, seja por 
operarem com excesso de reservas ou por poderem recorrer a empréstimos da autoridade monetária, não significa que esta não possa influenciar o processo endógeno de criação de moeda de crédito em que se baseia o presente modelo. Aqui, porém, essa influência se dá em nível de preço, por meio da taxa de juros básica, e não de restrições quantitativas. Da mesma forma, a assumida endogeneidade da moeda de crédito não implica a impossibilidade de os próprios bancos influenciarem o acesso efetivo a ela. No presente modelo, porém, essa influência assume a forma de restrições de acesso ao crédito via preço, não via quantidade.

O mark-up bancário, por sua vez, varia endogenamente ao longo do tempo, de acordo com o nível de atividade produtiva em relação a um nível exógeno de referência, ambos sendo medidos pelo grau de utilização da capacidade produtiva. Um comportamento pró-cíclico para o mark-up bancário significa que o sistema bancário deseja se apropriar de uma parcela maior do faturamento produtivo à medida que o nível de atividade econômica - e, portanto, a taxa de lucro total da economia - se eleva. Por seu turno, um comportamento anticíclico significa que uma elevação na utilização da capacidade, ao ampliar a capacidade potencial das firmas de servir um dado nível de endividamento, reduz seu risco percebido de inadimplência e, com isso, provoca uma redução no mark-up bancário.

Uma vez que as firmas produzem de acordo com a demanda efetiva sob condições de excesso de capacidade produtiva, a equalização entre investimento e poupança é alcançada por meio de variações na utilização da capacidade instalada. A existência de capacidade ociosa permite que as firmas concretizem seu investimento desejado, com a utilização da capacidade ajustando-se então para eliminar eventuais excessos de demanda ou de oferta. Nesse contexto, um aumento na taxa de juros, ao impactar negativamente o investimento das firmas, reduz as taxas de utilização da capacidade produtiva, de lucro total e de crescimento da economia.

Em termos dinâmicos, a focalização do par de variáveis juros-endividamento permitiu não somente analisar o comportamento da economia ao longo do tempo, mas, principalmente, relacionar suas propriedades de estabilidade diretamente à natureza do regime minskyano de financiamento prevalecen- 
te entre as firmas. Como visto, para níveis de juros inferiores à taxa de crescimento da economia predomina o regime de financiamento bedge mesmo para níveis muito elevados de grau de endividamento - para que valores de juros menores que a taxa de crescimento conduzam a um regime especulativo, é necessário que a economia se caracterize por uma propensão a poupar dos capitalistas muito elevada. Já para níveis de juros superiores à taxa de crescimento, o predomínio do regime Ponzi só não ocorrerá no caso de a economia encontrar-se em uma situação de grau de endividamento suficientemente baixo.

Se predominar o regime de financiamento hedge, o equilíbrio dinâmico do sistema será estável somente quando o mark-up bancário comportar-se de maneira pró-cíclica, ou seja, quando o sistema bancário desejar se apropriar de uma parcela maior do faturamento produtivo à medida que o nível de atividade produtiva - e, portanto, a taxa de lucro total da economia - se elevar. Quando, porém, o mark-up bancário é anticíclico, o equilíbrio dinâmico do sistema é instável. Portanto, mesmo uma economia em que prevalece o regime de financiamento hedge será dinamicamente instável caso uma maior utilização da capacidade produtiva, ao elevar a capacidade potencial das firmas de servir um dado nível de endividamento, reduza seu risco percebido de inadimplência e, com isso, provoque uma redução no mark-up bancário.

Prevalecendo, por sua vez, o regime de financiamento Ponzi, o equilíbrio dinâmico do sistema será necessariamente instável, independente do comportamento do mark-up bancário, embora este determine a natureza precisa dessa instabilidade. Especificamente falando, um mark-up bancário prócíclico provoca uma instabilidade do tipo ponto de sela, enquanto um anticíclico gera uma instabilidade do tipo nódulo. Portanto, também uma economia em que predomina o regime de financiamento Ponzi tem sua instabilidade dinâmica atenuada, ainda que aqui bastante parcialmente, por um comportamento pró-cíclico do mark-up bancário. 


\section{REFERENNCIAS BIBLIOGRÁFICAS}

ANGBAZO, L. Commercial bank net interest margins, default risk, interest-rate risk, and off-balance sheet banking. Journal of Banking and Finance, 21, 1997.

ARONOVICH, S. Uma nota sobre os efeitos da inflação e do nível de atividade sobre o spread bancário. Revista Brasileira de Economia, v. 48, n. 1, 1994.

BANCO CENTRAL DO BRASIL. Juros e spread bancário no Brasil. 1999. Mimeografado.

BROCK, P.; ROJAS-SUAREZ, L. Understanding the behavior of bank spreads in Latin America. Journal of Development Economics, v. 63, 2000.

DUTT, A. K. Accumulation, distribution and inflation in a Marxian/PostKeynesian model with a rentier class. Review of Radical Political Economics, v. 21, n. 3, 1989.

. Interest rate policy in LDCs: a Post Keynesian view. Journal of Post Keynesian Economics, v. 13, n. 2, 1990-91.

Rentiers in Post-Keynesian models. In: ARESTIS, P.; CHICK, V. (eds.), Recent developments in post Keynesian economics. Aldershot: Edward Elgar, 1992.

. On the long-run stability of capitalist economies: implications of a model of growth and distribution. In: DUTT, A. K. (ed.), New directions in analytical political economy. Aldershot: Edward Elgar, 1994.

FOLEY, D. K. Financial fragility in developing economies. New School University, 2001. Disponível em: http://cepa.newschool.edu/ foleyd.

KALECKI, M. Selected essays on the dynamics of the capitalist economy. Cambridge: Cambridge University Press, 1971.

LIMA, G. T. Progresso tecnológico endógeno, crescimento econômico e distribuição de renda. In: LIMA, G. T.; SICSÚ, J.; PAULA, L. F. de (orgs.), Macroeconomia moderna: Keynes e a economia contemporânea. Rio de Janeiro: Editora Campus, 1999.

. Market concentration and technological innovation in a dynamic model of growth and distribution. Banca Nazionale del Lavoro Quarterly Review, v. LIII, n. 215, December 2000.

LIMA, G.T.; MEIRELLES, A. J. Mark-up bancário, conflito distributivo e utilização da capacidade produtiva: uma macrodinâmica póskeynesiana. Revista Brasileira de Economia, v. 57, n. 1, Jan./Mar. 2003.

MEIRELLES, A. J. Moeda endógena e teoria monetária da produção. Revista de Economia Politica, v. 15, n. 3, 1995. 
. Moeda e produção: uma análise da polêmica pós-keynesiana sobre a endogenia monetária. Campinas: Mercado de Letras, São Paulo: Fapesp, 1998.

MINSKY, H. John Maynard Keynes. New York: Columbia University Press, 1975.

Can "it" happen again? Essays on instability and finance. New York: M. E. Sharpe, 1982.

ROBINSON, J. Essays in the theory of economic growth. London: Macmillan, 1962.

ROUSSEAS, S. A markup theory of bank loan rates. Journal of Post Keynesian Economics, v. 8, n. 1, 1985.

ROWTHORN, B. Demand, real wages and economic growth. Thames Papers in Political Economy, Autumn 1981.

SAUNDERS, A.; SCHUMACHER, L. The determinants of bank interest rate margins: an international study. Journal of International Money and Finance, 19, 2000.

STEINDL, J. Maturity and stagnation in American capitalism. New York: Monthly Review Press, 1952.

TAYLOR, L.; O'CONNELL, S. A Minsky crisis. Quarterly Journal of Economics, 100, 1985.

Registramos nosso agradecimento a Luiz Fernando de Paula e a dois pareceristas anônimos por úteis observações - vale, é claro, a isenção de praxe. Agradecemos ainda o suporte do CNPq, sob a forma de bolsas de Produtividade em Pesquisa.

tomze@ceres.fea.unicamp.br

giltadeu@usp.br

(Recebido em agosto de 2002. Aceito em abril de 2003). 